\title{
Inserção da Tecnologia no Ensino de Comunicação Social ${ }^{1}$
}

\author{
Paulo NEGRI FILHO
}

Glaucia da Silva BRITO

\section{Resumo}

Como o Parecer CES 492/2001 do Ministério da Educação não evidencia como as tecnologias devem ser inseridas no currículo de Comunicação Social, este estudo propõe uma reflexão a partir de metodologia em quatro fases, pesquisando estudantes, professoras, coordenadora e o currículo de uma Instituição de Ensino Superior localizada em Curitiba-PR que oferta as habilitações de Jornalismo, Publicidade e Propaganda e Relações Públicas. Os resultados permitem identificar a precariedade na abordagem tecnológica durante todo o curso e, em especial, na disciplina específica que trata da temática.

Palavras-chave: Currículo de Comunicação Social; Tecnologia da Informação e Comunicação (TIC); Graduação em Comunicação Social; Ensino Superior; Tecnologia e Comunicação Social.

\begin{abstract}
As the parecer CES 492/2001 of the Ministério da Educação does not show how technologies should be included in the curriculum of Social Communication's degree. So this study proposes a reflection with a methodology in four phases, researching with students, teachers, degree's coordinator and curriculum of an institution located in Curitiba-PR that offer qualifications in Journalism, Advertising and Public Relations. The results identify the precariousness technological approach throughout the course and in particular the specific discipline that deals with the theme.
\end{abstract}

Keywords: Social Communication's Curriculum; Communication and Information's Technology; Social Communication's Degree; Higher Education; Technology and Social Communication.

1 Trabalho apresentado à quinta edição da Revista Ação Midiática - Estudos em Comunicação, Sociedade e Cultura, publicação ligada ao Programa de Pós-Graduação em Comunicação, da Universidade Federal do Paraná.

2 Doutorando em Ciências da Comunicação - CAPES 5 (Unisinos), mestre em Educação - CAPES 5 (UFPR), especialista em Comunicação Visual em Mídias Interativas (Unopar) e bacharel em Comunicação Social - Publicidade e Propaganda (Imesa). Tem experiência na área de Comunicação, com ênfase em Videodifusão e Imprensa, atuando principalmente nos seguintes temas: Audiovisual, Tecnologia da Informação e Comunicação, Comunicação Corporal, Mídia Eletrônica, Mídia Impressa e Arte. Coordenador do curso de Publicidade, Propaganda e Marketing do Centro Universitário Internacional Uninter. Coautor do livro 'Produzindo textos com "velhas" e "novas" tecnologias' com a Prof. Dr. Gláucia da Silva Brito. Pesquisador do grupo de pesquisa "TV Digital no Brasil".

3 Possui Graduação em Bacharelado e Licenciatura Português Inglês pela Faculdade de Educação Ciências e Letras de Cascavel (1990), Especialização na Metodologia do Ensino Tecnológico pela Universidade Tecnológica Federal do Paraná (1994), Mestrado em Tecnologia pela Universidade Tecnológica Federal do Paraná (1997) e Doutorado em Linguística pela Universidade Federal de Santa Catarina (2002). Atualmente é professora adjunto da Universidade Federal do Paraná. Tem experiência nas áreas de Educação e Comunicação, com ênfase em Tecnologias da Informação e Comunicação, atuando principalmente nos seguintes temas: Comunicação e tecnologias, tecnologias na educação, professor e as tecnologias de informação e comunicação, educação a distancia e formação do professor, inclusão digital. 


\section{Graduação em comunicação social no Brasil}

Bordenave (1983, pp. 108-118) aponta para as diversas orientações que o estudo da Comunicação sofreu, enquanto evolução de nova ciência. O autor adverte, porém, que as orientações por vezes coexistem, sem necessariamente excluírem-se, por vezes completandose orientação para os conteúdos, orientação para os códigos, orientação para os meios e seus efeitos, orientação para a difusão de inovações, orientação para a transmissão de informação, orientação para as funções da comunicação, orientação para a estrutura social e orientação para a mudança social.

Informações disponíveis no Portal do INEP (Instituto Nacional de Estudos e Pesquisas Educacionais Anísio Teixeira) fornecem o Censo da Educação Superior 2011 (datado de abril de 2013), mas sem dados detalhados por curso, sendo os mais recentes de $2008^{4}$, dando conta de que no Brasil existiam 619 cursos/habilitações de Comunicação Social ofertados tanto em instituições públicas quanto privadas, nas diversas habilitações. Detalhando o recorte por regiões, ao se pesquisar os cursos de Comunicação Social no Brasil tanto em instituições públicas quanto privadas, tem-se:

\section{Região Norte - 37 cursos/habilitações ofertadas; \\ Região Nordeste - 109 cursos/habilitações ofertadas; \\ Região Centro-Oeste - 60 cursos/habilitações ofertadas; \\ Região Sudeste - 308 cursos/habilitações ofertadas; e \\ Região Sul - 105 cursos/habilitações ofertadas.}

Ainda que a metade do total nacional dos cursos/habilitações sejam ofertados na região Sudeste, e apenas $17 \%$ na região Sul, seguindo o recorte da pesquisa proposta, tem-se que no estado do Paraná existem 44 cursos/habilitações ${ }^{5}$ de Comunicação Social ofertadas pelo total das instituições de Ensino Superior, conforme o MEC, sendo que, desse total, 33 habilitações ${ }^{6}$ são ofertadas na capital do estado, a cidade de Curitiba.

São onze instituições privadas de Ensino Superior na cidade de Curitiba que ofertam a graduação em Comunicação Social em suas diversas habilitações e apenas uma instituição pública Federal, ofertante das habilitações de Jornalismo, Relações Públicas e Publicidade e Propaganda.

Das doze instituições da cidade, onze possuem cursos de Comunicação Social

4 [http://www.educacaosuperior.inep.gov.br/funcional/lista_cursos.asp], consultado em janeiro de 2008.

5 Os dados on-line do MEC são apresentados de forma mesclada entre cursos e habilitações, não significando o total real de habilitações ofertadas.

6 O MEC apresenta os dados de Curitiba-PR como: 18 habilitações/cursos de Comunicação Social, sendo que o total real de habilitações ofertadas é de 33, somando-se as 13 instituições de Ensino Superior presentes na cidade. 
relativamente jovens, com data de início de funcionamento a partir de 1994 até 2007. Os cursos mais antigos são encontrados na Universidade Federal do Paraná (UFPR) e na Pontifícia Universidade Católica do Paraná (PUCPR), sendo assim datados:

$$
\begin{aligned}
& \text { Jornalismo - } 1956 \text { (PUCPR) e } 1969 \text { (UFPR); } \\
& \text { Publicidade e Propaganda - } 1977 \text { (UFPR) e } 1989 \text { (PUCPR); e } \\
& \text { Relações Públicas - } 1977 \text { (UFPR) e } 1995 \text { (PUCPR). }
\end{aligned}
$$

Apesar das diferentes habilitações, a Comunicação Social é um curso que mantém um núcleo curricular comum, além de objetivos colocados pelas Diretrizes Curriculares compartilhados por todas as habilitações. Os formandos devem sair do curso com um perfil de formação geral que independe da habilitação, conforme o Parecer CES 492/2001 (p. 16) do MEC. Isto garante a identidade do curso.

O Parecer ressalta as capacidades relacionadas às mídias, fundamentais na profissão do comunicador social. Já no segundo tópico, a qualidade do formando ressaltada é a habilidade de reflexão com relação à mutabilidade, complexidade e velocidade do mundo contemporâneo.

$\mathrm{O}$ MEC ainda privilegia nos tópicos 3 e 4 que o egresso tenha uma visão comunicacional ampla e especializada das relações com os processos sociais, e que saiba utilizar criticamente o instrumental teórico-crítico da Comunicação Social.

Existem, ainda, competências e habilidades apontadas pelo Ministério da Educação como sendo fundamentais na formação dos comunicadores sociais, essas competências e habilidades são bases para uma formação consistente, em que o formando em Comunicação Social terá condições de assimilar conceitos de forma crítica, permitindo a apreensão de teorias; colocar em prática tais conceitos e teorias para que sejam feitas análises críticas da realidade, com posicionamento ético-político; dominar as linguagens comunicacionais, em todas as suas dimensões, fazendo a experimentação e podendo inovar no uso de tais linguagens; refletir criticamente sobre as práticas profissionais da Comunicação e sendo competente no uso da língua nacional nas diversas situações exigidas pela profissão.

Outro ponto presente no documento do MEC é o dos Conteúdos Curriculares, os quais são diferenciados entre Básicos e Específicos, sendo que "os conteúdos básicos são aqueles relacionados tanto à parte comum do curso quanto às diferentes habilitações" e "os conteúdos específicos são aqueles que cada instituição, livremente, deve eleger para organizar seu currículo pleno, tendo como referência os objetivos e os perfis comuns e específicos anteriormente definidos" (op. cit., p. 23).

Embora ambos os conteúdos tenham importância para a graduação, destacam-se os conteúdos Básicos, pois esse tipo de conteúdo é comum às diversas habilitações da Comunicação 
Social, conforme definido pelo MEC. Cada categoria apresentada deve estar presente nas discussões do núcleo comum do curso, sendo:

- conteúdos teórico-conceituais;

- conteúdos analíticos e informativos sobre a atualidade;

- conteúdos de linguagens, técnicas e tecnologias midiáticas; e

- conteúdos ético-políticos.

Das quatro categorias de conteúdos Básicos, uma pode ser destacada por representar a questão a que se propõe este estudo, 'a categoria dos conteúdos de linguagens, técnicas e tecnologias midiáticas'.

Esta categoria é a que dá subsídios para que os cursos de Comunicação Social brasileiros adentrem à questão tecnológica da comunicação. Apesar de serem pontos fundamentais no estudo da comunicação e no desenvolvimento pleno do comunicador social, as Diretrizes Curriculares não são claras nos elementos que devem compor essas categorias, ficando a cargo das instituições a composição do currículo da forma que julguem melhor estruturada para a formação de seus estudantes.

Ou seja, as Diretrizes Curriculares do MEC aos cursos de Comunicação Social, embora privilegiem a inclusão dos conteúdos relacionados às Tecnologias da Informação e Comunicação $(\mathrm{TICs})^{7}$, não explicitam a forma, a nomenclatura ou a periodização para o estudo dessa temática nos currículos acadêmicos.

Dessa forma, a Comunicação deve ser pensada e discutida entre professores e estudantes para que o currículo seja moldado da melhor forma possível. Pois formar profissionais de Comunicação Social é focar no fato de que os mesmos atuarão junto à sociedade e que isto pede uma consciência de responsabilidade altamente desenvolvida. Além de se tornarem responsáveis pela comunicação, divulgação de notícias, eventos, anúncios, propagandas, publicidades, sejam para empresas públicas ou privadas, seja como empregados ou empregadores, se tornarão, também, responsáveis pela forma como comunicam e pelo objeto que comunicam para uma sociedade toda ou parte dela. Os estudantes de Comunicação Social não se formam simplesmente comunicadores, mas comunicadores sociais, e isto gera novas implicações nesta formação.

Para Wolton (2004) existe um ponto de intersecção, comum aos três níveis de

7 Os autores optaram por utilizar o termo na maneira que parece ser a mais próxima de sua concepção: TICs. A opção também se justifica porque tratar TICs por NTICs, Novas Tecnologias da Informação e Comunicação, ou TDICs, Tecnologias Digitais da Informação e Comunicação, soam, em ambos os casos, como terminologias muito restritivas. Na primeira situação pelo fato de que quando se fala em Tecnologia, em pouco espaço de tempo fica obsoleto, o que dificultaria estabelecer o que são "novas" tecnologias. Perspectiva equivocada, então, amplamente disseminada pelos meios de comunicação e apropriada pelo senso comum. Já no segundo caso, parece redundante acrescentar o "digitais" a um termo que já surgiu exatamente pelo caráter que somente as tecnologias digitais proporcionam. 
comunicação (direta, técnica e social): a 'interação'. Já que, para o autor, é a interação que define a comunicação. Essa interação acontece entre indivíduos reflexivos. E é certo que os indivíduos têm capacidade de pensar, refletir e criticar, tanto que uma das preocupações de Paulo Freire foi desenvolver nos educandos o senso crítico, e possibilitar a essas pessoas a capacidade de fazer uma leitura crítica dos meios de comunicação, da vida.

Melo conclui que "o homem integrado no seu mundo faz cultura" (1998, p. 259, grifo original). $\mathrm{O}$ autor busca em Freire subsídios para afirmar que "a partir das relações do homem com a realidade, resultante de estar com ela e de estar nela, pois atos de criação, recriação e decisão, vai ele dinamizando o seu mundo" (ibid., grifo original). De forma oposta, tem-se o homem massificado, que, ainda em contato com a realidade, não está integrado a ela. Freire acrescenta, este homem é "denominado pela força dos mitos e comandado pela publicidade organizada" e "vem renunciando cada vez mais, sem o saber, à sua capacidade de decidir" (apud MELO, 1998, p. 259).

Para Melo a cultura do silêncio é um fenômeno comum aos povos colonizados, fenômeno que Freire chama de "mutismo" do homem brasileiro, de uma sociedade caracteristicamente fechada, "colonial, escravocrata, sem povo, reflexa, antidemocrática" (MELO, 1998, p. 263). Esse "mutismo" foi, posteriormente, denominado por Freire de "cultura do silêncio" (op. cit., p. 265), característica de todos os povos colonizados, com raízes na prática secular da "incomunicação" (ibid.). Por isso Freire apresenta ao mundo uma "Pedagogia do Oprimido", já que o homem “colonizado é silencioso, é alguém que não tem voz própria, que fala pela fala do opressor" (ibid.).

A 'Pedagogia do Oprimido', além de ser uma 'Pedagogia da Comunicação', que, “implicando na comunhão do educador e do educando, afigura-se como uma pedagogia aberta, em permanente reelaboração. Quando mais intensa a comunicação, mais rica a interação entre os participantes" (op. cit., p. 266), é, também, uma pedagogia libertadora, pela comunicação, alcança-se a libertação.

Melo acrescenta que "a comunicação só se faz autenticamente com liberdade. Por sua vez, a liberdade só se conquista com comunicação" (ibid.). E a comunicação, para Canclini, assumiu destaque especial na sociedade contemporânea, em que as grandes massas "podem viver sem a Escola, porém já não vivem sem a Comunicação. É da Comunicação que alimentam seu imaginário, constroem suas representações, encontrando a síntese para a complexidade da vida moderna" (apud SOARES, 1999, p. 52).

A comunicação eficiente, para Freire, é o 'modo dialógico de interação', para ele "ser dialógico é vivenciar o diálogo, é não invadir, é não manipular, é não sloganizar. O diálogo é o encontro amoroso dos homens que, mediatizados pelo mundo, o pronunciam, isto é, o transformam e, transformando-o, o humanizam" (FREIRE, 1976 apud SOARES, 1999, p. 55). 


\section{O currículo de comunicação social nesta pesquisa}

O currículo é o documento comprobatório daquilo que o estudante deve tomar conhecimento durante sua formação, "uma estrutura de conhecimento socialmente apresentado, externo ao conhecedor, a ser por ele dominado" (GREENE, 1971, apud GOODSON, 1995, p. 18), incluindo "un conjunto de principios sobre cómo deben seleccionarse, organizarse y transmitirse el conocimiento y las destrezas" (LUNDGREN, 1997, p. 20). Mas em um mesmo curso, como o de Comunicação Social, existem vários currículos, com variações significativas, em especial quando o ponto em questão é uma disciplina que se propõe a "ensinar" uma temática nova, ainda em movimento.

el "curriculum" es uno de los conceptos claves en la educación y constituye una de las áreas más importantes de la investigación educativa. Desde este punto de vista, sería de esperar que el campo de la teoría curricular estuviera bien desarrollado, pero incluso un simple repaso a la literatura curricular revela que esto no es así (op. cit., p. 71).

Esta citação indica a pequena quantidade de bibliografia e dificuldade no desenvolvimento da teoria curricular, possivelmente pela sua complexidade e diversas facetas que conjuntamente formam este importante elemento da educação. Ao mesmo tempo a afirmativa também apoia a justificativa do estudo a que se propõe este artigo. E, embora existam outros motivos tão concretos quanto o do estudo do currículo propriamente dito, é necessário analisar este documento na graduação de Comunicação Social, já que a preocupação colocada já nos objetivos apontados logo no início do texto, mais especificamente, é o da inserção das TICs enquanto disciplina e seu código disciplinar no curso de Comunicação Social, e assim, de que forma o currículo pode trazer esta temática à realidade dessa graduação.

Bueno e Brito (2005) entendem que a estruturação desta disciplina pode ser uma inovação necessária aos currículos do curso de Comunicação, especialmente se forem consideradas as necessidades atuais, inclusive da sociedade. A estruturação se faz necessária porque "não é possível pensar numa disciplina que limite a tecnologia à condição de objeto, recurso, técnica, matéria. É fundamental ampliá-la, para que alunos tenham a possibilidade de, diante de um mercado embora competitivo, entender que podem optar" (BUENO \& BRITO, 2005, p. 5).

Segundo as pesquisadoras (op. cit., pp. 4-5), alguns estudantes começaram a perceber um círculo construtivo em que se correlacionam arte-técnica-tecnologia, num processo comunicativo. Dessa forma, além da análise do currículo de Comunicação Social, faz-se necessário conhecer as necessidades dos estudantes e, também, a opinião prática dos professores que estão inseridos nesse contexto da docência dessas disciplinas que contemplam as TICs na graduação. 


\section{Estabelecendo relações a partir de pesquisa empírica}

Aqui, pretende-se explicitar os caminhos teóricos e práticos percorridos no estudo, na tentativa de que seja alcançada resposta para a questão norteadora da pesquisa: quais seriam os elementos curriculares básicos necessários à disciplina específica de Tecnologia para uma formação prático-reflexiva em relação às TICs do comunicador social em qualquer uma de suas habilitações?

A metodologia adotada é a Pesquisa Qualitativa, já que "estudos qualitativos permitem iluminar o dinamismo interno das situações, geralmente inacessível ao observador externo" (LÜDKE \& ANDRÉ, 1986, p. 12). Por meio deste tipo de pesquisa, pretende-se explorar o currículo de Comunicação Social, sob a luz do dinamismo interno que a pesquisa qualitativa proporciona. Apoiado na importância da fundamentação teórica geral do que se está estudando, o trabalho do pesquisador, conforme Triviños (1987, pp. 131-132), "se realiza no processo de desenvolvimento do estudo. A necessidade de teoria surgirá em face das interrogativas que se apresentarão". Assim, a pesquisa qualitativa será construída ao longo do percurso de estudo do campo, reflexão da temática, coleta de dados, sua análise e novas possibilidades que estas ações possam apresentar.

Com essa liberdade apontada por Triviños, somada à perspectiva de um estudo coerente, que sane as expectativas geradas no campo pesquisado, respondendo a questão norteadora, apresentam-se as explorações realizadas até o momento nesta metodologia.

A partir de uma abordagem qualitativa estrutura-se a pesquisa em quatro fases distintas:

'Primeira fase': entrevista com perguntas semi-estruturadas, agora, realizada com um graduando de cada habilitação de Comunicação Social, concluintes do curso, sendo três formandos entrevistados da mesma instituição, "U";

'Segunda fase': entrevista semi-estruturada feita com a coordenadora do curso de Comunicação Social da "Instituição U";

'Terceira fase': entrevista com professoras da disciplina 'Comunicação e Tecnologia' da "Instituição U”, presente na formação básica de Comunicação Social e obrigatória a todas as habilitações; e

'Quarta fase': análise documental (BARDIN, 2004, p. 39-41) realizada com o Plano de Ensino da disciplina 'Comunicação e Tecnologia' da referida instituição.

A entrevista semi-estruturada adotada na 'Primeira', 'Segunda' e 'Terceira' fases, de acordo com Triviños (1987, p. 145), é um importante meio para realizar a coleta de dados, pois, ao mesmo tempo em que valoriza a presença do investigado, possibilita que o informante alcance a espontaneidade, enriquecendo a investigação.

Lüdke e André (1986, p. 36) complementam sobre a necessidade de o pesquisador ficar atento não somente ao roteiro já estabelecido, mas às expressões, entonações de voz, 
sinais não-verbais, hesitações, alterações de ritmo — ou seja, toda comunicação não-verbal é fundamental para compreender e validar a fala dos pesquisados. Em função do caráter qualitativo que esta investigação apresenta, a coleta desses dados nas quatro primeiras fases foi realizada de forma flexível, respeitando a individualidade de cada entrevistado. As perguntas formuladas para as entrevistas refletem as questões teóricas dos principais interesses neste artigo.

Segundo Patton (1990, p. 169), um dos itens que diferencia uma pesquisa qualitativa de uma quantitativa é a abordagem da amostra, pois, no caso da qualitativa, os participantes são escolhidos propositadamente, visando a selecionar casos específicos cujo estudo iluminará as questões investigadas. Casos específicos - information-rich cases - são aqueles pelos quais se pode aprender muito sobre um assunto que seja de importância central para o propósito da pesquisa, por isso o termo "amostra intencional" ou, como escreve Patton (1990), purposeful sampling.

De acordo com Triviños (1987, p. 160), ao realizar este tipo de análise, ocorre uma interação entre os materiais, não devendo o pesquisador restringir sua interpretação ao conteúdo manifestado. Deve-se, ainda, tentar aprofundar a análise e desvendar seu conteúdo latente, de modo a revelar as características do tema em estudo - no caso deste trabalho, o da inserção das TICs na graduação em Comunicação Social.

A Análise de Conteúdo, então, refere-se a um conjunto de técnicas que objetiva a compreensão não só da fala explícita dos entrevistados, mas também do conteúdo latente, aquele que está subentendido nas mensagens que os entrevistados transmitem inclusive através de reações físicas. Triviños (1987, p. 160), ao interpretar o texto de Bardin sobre Análise de Conteúdo, considera esse método um caminho para estudar a comunicação entre os homens, enfatizando o conteúdo das mensagens.

A 'Quarta fase' da pesquisa, diferentemente das anteriores, privilegia o método de Análise Documental, já que, para Chaumier (1974) este tipo de análise pode ser definida como "uma operação ou um conjunto de operações visando representar o conteúdo de um documento sob uma forma diferente da original, a fim de facilitar num estado ulterior a sua consulta e referenciação" (apud BARDIN, 2004, p. 40). Assim, por meio de procedimentos de transformação, a Análise Documental permite o acesso sistematizado ao conteúdo primário (em bruto) disponível, agora em forma de documento secundário (representação do primeiro) que permite a consulta conforme a classificação feita para futuras análises e interpretações.

O tipo de documento apresentado na 'Quarta fase' desta pesquisa pode ser caracterizado como oficial, sendo o Plano de Ensino da disciplina 'Comunicação e Tecnologia' aprovado de acordo com as normas do MEC pelo setor responsável dentro da instituição selecionada para a pesquisa. 


\section{Primeira fase - entrevista com concluintes do curso}

A entrevista fez cair a hipótese de que ao cursar a disciplina 'Comunicação e Tecnologia' os conceitos tecnológicos se fundamentariam na sua relação com a Comunicação para os estudantes. As respostas demonstram, ainda, certo descontentamento com a abordagem feita ao campo pela disciplina.

Os estudantes não demonstram segurança para definir o conceito de tecnologia, resumindo-se a respostas de que a tecnologia está ligada à modernidade e ao aperfeiçoamento de técnicas. Essas respostas apontam para as respostas dadas na fase anterior, com grupo de estudantes que ainda não haviam cursado a disciplina 'Comunicação e Tecnologia'.

Quando se delimita o campo, especificando as TICs, há uma tentativa de explicar o termo por meio de sua estrutura semântica, caindo, na maioria dos casos, em conceitos de senso comum ${ }^{8}$.

Os elementos apresentados como os mais marcantes no decorrer do curso são muito pontuais e tão poucos que se poderia crer, a partir do contexto externo, que o curso não contempla o estudo das TICs, apesar de ter disciplina específica para a discussão do tema.

Um dos exemplos de elementos de TICs foi a própria disciplina 'Comunicação e Tecnologia', os outros foram a "convergência midiática", tema de um dos seminários da mesma disciplina e "técnicas básicas de TV" e "técnica de comunicação aproximativa", assuntos abordados em outros momentos do curso.

Para os entrevistados, pouquíssimas disciplinas adentraram ao campo das TICs, ficando os exemplos restritos à disciplina 'Comunicação, Sociedade e Cultura' e 'Comunicação e Linguagem'.

Com relação a propostas de alteração na disciplina 'Comunicação e Tecnologia', as sugestões foram bastante consistentes, relacionadas, principalmente com a inserção de projetos, mudanças metodológicas e didáticas.

Cada um dos pontos colocados pelos entrevistados ajuda a repensar a disciplina em questão e, também, o ensino de TICs e a forma como está inserido na graduação de Comunicação Social. Os estudantes não conseguiram identificar muitas ocasiões em que tiveram contato com o ensino das TICs ao longo da graduação, esse fato pode se dar pela falta de consciência da abrangência do campo em que eles reconhecem ter uma percepção ainda rasa.

8 Chauí explicita as características do senso comum, apresentando-as como de caráter: subjetivo; qualitativo; heterogêneo; individualizador; generalizador; estabelecem relações de causa e efeito entre as coisas e entre os fatos; não se surpreendem e nem se admiram com a regularidade, constância, repetição e diferença das coisas; identificam ciência com magia. (ver: CHAUÍ, Marilena. Convite à Filosofia. São Paulo : Ática, 2000. Unidade 7, capítulo 1.) 


\section{Segunda fase - entrevista com coordenadora do curso}

A entrevista com a coordenadora do curso se justifica pelo fato de a coordenação possuir proximidade com o currículo e ementas, sendo capaz de responder as questões necessárias ao esclarecimento dos objetivos colocados.

O roteiro para a entrevista semiestruturada (VIEGAS, 2007, pp. 110-114) foi elaborado a partir das discussões realizadas na pesquisa-piloto, em estágio de docência, além daquelas questões levantadas na primeira fase pelos concluintes do curso.

Ao se referir sobre a relação das TICs com a Comunicação Social, a professora coordenadora acredita que a "própria discussão da comunicação incorpora a questão da tecnologia. Faz parte da própria história da Comunicação. A importância dela é justamente estar e estimular os avanços que temos na área de Comunicação". Ela aponta a disciplina 'Comunicação e Tecnologia' como estando diretamente ligada ao estudo do campo das TICs. A coordenadora analisa a disciplina como sendo de cunho teórico, acrescenta que a prática fica a cargo das disciplinas mais voltadas para os laboratórios.

Sobre a localização da disciplina no $7^{\circ}$ período do curso, a coordenadora afirma que o currículo do curso está sendo revisto e, que de alguma forma, outras disciplinas em momentos diferentes do curso também abordam a discussão tecnológica. A coordenadora apresenta dois pontos diferentes sobre a relação da disciplina 'Comunicação e Tecnologia' em momentos diferentes do curso, que a disciplina poderia abrir a discussão do tema no início do curso e que a disciplina no $7^{\circ}$ período é interessante, já que neste momento os estudantes já estão mais amadurecidos, podendo aprofundar as discussões.

A disciplina, atualmente, é ofertada por apenas um semestre, tempo que não seria suficiente para o estudo do campo das TICs, conforme opinião da coordenadora. Além desse fator, faltam aparatos tecnológicos atualizados, outra fragilidade do curso.

Contudo, um ponto positivo destacado pela coordenadora é o fato da abordagem ao tema ser mais científica, característica da instituição.

Ela destaca a dificuldade de atualização de equipamentos tecnológicos, já que as mudanças acontecem muito rapidamente e acaba se tornando impossível ter laboratórios totalmente atualizados. Além da escassez e burocracia para liberação de recursos financeiros com esse fim.

Outras disciplinas adentram o campo das TICs no decorrer do curso, conforme informa a entrevistada e, apesar da falta de atualização dos aparatos tecnológicos, o aprendizado básico está garantido com equipamentos um pouco mais antigos, mas que dão conta dos elementos gerais das TICs.

Para a coordenadora, "esse aperfeiçoamento técnico também, eles (estudantes) podem conseguir em vários outros cursos profissionalizantes que são ofertados no mercado. A 
universidade, me parece, não deve se preocupar tanto com essa questão. Eu ainda entendo que a abordagem teórica é mais importante que essa abordagem técnica a respeito da tecnologia." A abordagem teórica deve sim, ser priorizada, já que a universidade deve formar cidadãos reflexivos e com consciência crítica. Porém, por todos os pontos levantados até aqui, seja impossível menosprezar a necessidade de prática que as TICs assumem na formação de Comunicação Social, conforme o colocado pelas Diretrizes Curriculares do MEC no PARECER CES 492/2001, em que não são priorizados nem os conhecimentos teóricos nem os práticos, mas ambos como complementares.

Os recursos tecnológicos disponíveis não podem ser ignorados, já que, como a coordenadora coloca, uma universidade pública tem diversas dificuldades de atualização nesses termos, embora, conforme entrevista feita com o professor "E" demonstre a possibilidade de se trabalhar questões práticas sem, necessariamente, estar de posse dos aparatos aos quais a prática se refere.

Sobre as experiências com projetos-integrados, citados pelos formandos entrevistados, a coordenadora declara que algumas experiências têm sido feitas, com disciplinas integradas. Ela percebe os resultados como positivos e acredita que com as discussões da reforma curricular, os projetos serão algo decorrente, na medida em que os professores forem se encontrando e discutindo as questões.

$\mathrm{Na}$ próxima fase foram entrevistadas as duas últimas professoras substitutas que ministraram a disciplina 'Comunicação e Tecnologia'.

\section{Terceira fase - entrevista com professoras}

Há um consenso entre todos os entrevistados das fases anteriores sobre a importância da temática das TICs relacionadas à da Comunicação Social. Da mesma forma, as professoras "N" e "J" concordam que "a discussão de tecnologia é necessária porque ela vai fazer parte da vida do comunicador, não importa onde ele vá trabalhar, a tecnologia estará presente" $(\mathrm{N})$, sendo necessário que "a gente, dentro de uma faculdade de Comunicação entenda o porquê do início, da entrada dessas novas tecnologias para poder saber como utilizar, como entender essas tecnologias dentro de uma sociedade" (J).

As professoras divergem quando questionadas sobre o caráter da disciplina, "J" percebendo como fundamentalmente teórica e "N" acreditando ter a disciplina um caráter misto. Contudo, pelas conversas com as professoras, pode-se identificar o motivo da disparidade.

"J" percebe a disciplina como teórica, já que dá sua resposta respaldada pela ementa e conteúdo programático da mesma, "essa questão dela ser bem teórica é estranha, é uma ambiguidade, porque você vai trabalhar com tecnologias que são eminentemente práticas [...] o ideal seria que tivesse tanto a parte teórica quanto a parte prática, dividir essas aulas, por exemplo". 
A professora "N" tem a disciplina como mista devido à metodologia aplicada por ela nas aulas, já que para ela, essa "é uma disciplina para se pensar a prática. Esclarecer para os estudantes o que é a Comunicação de um lado e o que é a Tecnologia de outro, e como ambas se relacionam. Para isso é necessário ir a campo. Associar a teoria à prática”.

Neste caso, a disciplina foi dividida em dois bimestres, sendo que no primeiro bimestre assumiria um caráter mais teórico, com seminários, artigos, para que os estudantes entendessem o campo, enquanto no segundo bimestre a professora " $\mathrm{N}$ " procurava direcionar para a área de cada um, das três habilitações, de forma mais prática, com aproximação da realidade profissional das TICs na Comunicação.

Para "N", a questão metodológica é fundamental para o aprendizado, sendo base da prática docente. "Sem uma metodologia pensada especificamente para o assunto que será trabalhado se torna muito difícil conseguir fazer com que o conteúdo seja absorvido pelos estudantes".

A professora "J" avalia que falta à metodologia da disciplina uma contrapartida prática, sugerindo que "essa é uma disciplina de trinta horas, poderia, por exemplo, fazer numa semana sim outra não, uma coisa mais prática”. Ela acredita ser fundamental que os estudantes manipulassem os elementos que veem na teoria.

Na experiência da professora "N", a desmistificação tanto do conceito de Comunicação, quanto do de Tecnologia seria importante, "a Tecnologia enquanto conceito pensando que esta é um processo humano e, dessa forma, se liga à Comunicação, já que todo processo humano se dá pela Comunicação". Outro elemento destacado como fundamental por "N" é a vivência em campo, para isto a professora "procurava criar espaços dinâmicos, para que os estudantes se envolvessem, se sentissem na obrigação de participar, tudo de acordo com a metodologia que já havia sido pensada anteriormente".

Ao passo que a professora "J" pensa nos autores que sustentam a parte teórica da disciplina, acreditando ser "mais interessante tentar não só pegar os autores mais tradicionais dessa área", mas também, "autores que trabalhem, por exemplo, o uso dessas novas tecnologias na Comunicação, pesquisas que estão sendo feitas em Comunicação e o uso em novas tecnologias". Ela acha importante levar para a sala, estudos de casos, a prática da Comunicação relacionada às novas tecnologias.

"J" somaria, ainda, para melhorar a disciplina, seminários com "profissionais das diversas áreas pra comentar essa parte mais prática, profissionais que trabalhem em empresas, por exemplo". A professora acredita ser benéfico para os estudantes o contato com profissionais, com a realidade, a aplicabilidade das TICs na Comunicação.

A professora "N" é enfática ao afirmar que "faltou interdisciplinaridade, com disciplinas específicas de cada habilitação somadas à de 'Comunicação e Tecnologia', e isto acontece porque na época não havia um Projeto Pedagógico que desse condições para que esse diálogo 
entre as disciplinas acontecesse".

Ambas as entrevistadas concordam que a disciplina se encontra no momento adequado do curso, porque "nesta fase o estudante já passou por disciplinas básicas que vão dar suporte para as discussões levantadas em 'Comunicação e Tecnologia"” (N). Contudo "J" ressalta que mesmo assim, os estudantes muitas vezes chegam sem o embasamento teórico necessário para o aprofundamento das questões, sendo forçada à revisão de alguns autores. Ela ainda critica o fato da disciplina estar inserida no mesmo momento em que se inicia o 'TCC 1', o que geraria uma "briga" pela atenção do estudante, já que a atenção ao projeto para a conclusão do curso acaba sendo mais contundente. Ela afirma que "eles (os estudantes) fazem (a disciplina) muitas vezes só pra cumprir, eles faltam bastante, só querem saber quando tem avaliação, quando é o seminário".

Há concordância ao serem questionadas sobre o tempo de duração da disciplina, de um semestre, em que ambas afirmam, indo ao encontro da resposta da coordenadora do curso, que "sem dúvidas não" é suficiente para o desenvolvimento da temática com os graduandos.

As professoras justificam que a disciplina tem a discussão muito densa que não é possível permanecer com os mesmos teóricos, que há necessidade de atualização. A professora "J" propõe que "poderia ter uma optativa para cada uma delas (habilitações) para ter essa questão (prática), aí sim deveria ser uma disciplina ofertada separada, mais um semestre pra cada aluno".

A última fase, que somada às anteriores dá subsídios para a análise da realidade da inserção das TICs no curso de Comunicação Social da "Instituição U”, é a análise documental do Plano de Ensino da disciplina 'Comunicação e Tecnologia'.

\section{Quarta fase - o documento}

Os estudos ficaram concentrados na "Instituição U”, ofertante da disciplina 'Comunicação e Tecnologia', conforme as fases anteriores apresentaram. A instituição ficou aberta ao estudo, disponibilizando, além do contato com estudantes, professores e coordenadora e o Plano de Ensino da disciplina.

Metodologicamente esta fase apoia-se na Análise Documental (BARDIN, 2004, pp. 3941). A disciplina 'Comunicação e Tecnologia' é parte comum do currículo de Comunicação Social da "Instituição U”, sendo obrigatória a todas as habilitações do curso. A mesma não possui pré-requisitos para ser cursada e tem a periodicidade de um semestre, totalizando 30 horas/aula.

Embora a disciplina adentre ao campo tecnológico, as horas/aula são fundamentalmente teóricas, o que, como declara a professora "J", entrevistada na terceira fase é "uma ambigüidade, porque você vai trabalhar com tecnologias que são eminentemente práticas [...] o ideal seria

9 Primeira parte do Trabalho de Conclusão de Curso. 
que tivesse tanto a parte teórica quanto a parte prática, dividir essas aulas, por exemplo". Esta visão da professora "J" se dá pelo fato de que, segundo ela, o Plano de Ensino da disciplina é fundamentalmente teórico, mas como ela apresenta agora, "o ideal seria que tivesse tanto a parte teórica quanto a parte prática".

O Programa da disciplina não apresenta nenhum tópico que trata exclusivamente da conceituação de Tecnologia, sendo aparentemente pouco ponderado o estudo da relação com a Comunicação, sem que antes tenha sido estudado o campo tecnológico mais a fundo pelos estudantes. Esta afirmação pode ser apoiada na Bibliografia Mínima apresentada no Plano de Ensino, em que não existem obras que abordem a temática tecnológica no âmbito da conceituação e historicidade.

A professora "N", na 'Quarta fase', afirmou que, conforme sua experiência, seria necessário desmistificar as Tecnologias junto aos estudantes e, então, a Comunicação, para que somente depois se iniciassem as discussões relacionais entre os dois campos.

Os Procedimentos Didáticos permanecem com caráter tradicional, com uso de poucos recursos, apesar da disciplina possibilitar uma infinidade de abordagens que ajudariam os estudantes em uma aprendizagem sinestésica, que não se limitasse ao visual ou auditivo, contemplando outros sentidos importantes para a interiorização dos conteúdos abordados. Além do que, foi um dos pontos levantados pelo formando na 'Segunda fase' pelo estudante “D”, em que foi sugerida por ele a utilização de recursos audiovisuais para o desenvolvimento da disciplina de forma mais sinestésica, alcançando os mais diferentes perfis de aprendizado de cada estudante.

A aproximação com o campo de estudo, o da relação tecnologia-comunicação, não aparece no Plano de Ensino, sendo uma das características da metodologia apresentada pela professora "N" quando afirma que "é uma disciplina para se pensar a prática. Esclarecer para os estudantes o que é a Comunicação de um lado e o que é a Tecnologia de outro, e como ambas se relacionam. Para isso é necessário ir a campo, associar a teoria à prática”.

Contudo, faz-se necessário uma aproximação dos dados de todas as fases, a fim de que a questão norteadora da pesquisa seja respondida, ou pelo menos, tenha indícios de resposta.

\section{Aproximando as quatro fases}

Goodson (1995) diz respeito à 'vitalidade' que o currículo possui, podendo ser modificado de acordo com as necessidades que surgem, conforme a evolução das coisas e pessoas à sua volta. O autor atenta para a possibilidade de o currículo ser diferente para diferentes sujeitos, dependendo de fatores sociais.

Não é papel deste estudo 'maquiavelizar' o currículo, mas, ao mesmo tempo, não se pode apresentar uma consciência ingênua da força que o currículo tem na sociedade e na formação 
das pessoas, desde as séries primárias do ensino até a pós-graduação, já que foram apresentados anteriormente fatores históricos, sociais, políticos, econômicos, de classe, de gênero, dentre outros que estão direta ou indiretamente ligados à construção e execução prática do currículo.

Não só o documento oficial do governo privilegia o estudo da Tecnologia no curso de Comunicação Social, assim como todos os entrevistados, sejam estudantes, professores ou coordenadora de curso, e teóricos da área reconhecem a importância dessa temática ao campo comunicacional atual.

A falta de clareza do conceito pelos estudantes pode ser explicada não só pela ausência de atividades de caráter mais prático na disciplina, como reclamaram, mas, além disso, pelo fato de o Programa da disciplina e sua Bibliografia Básica não incorporarem conteúdos conceituais do campo tecnológico especificamente.

A abordagem da Tecnologia na disciplina já acontece na relação com a sociedade e, então, com a comunicação, não havendo, aparentemente, espaço para a "desmistificação da Tecnologia" em separado, como colocou a professora "N".

Outro fator que pode colaborar com a dificuldade de clareza do tema é a falta de uma linha estrutural que permita à disciplina se desenvolver do campo mais amplo para o mais especializado. Como foi colocado pelos estudantes entrevistados, quando disseram que os seminários trazem temáticas escolhidas por eles próprios de forma aleatória, sem uma ligação de "raciocínio" (estudante "F") entre os temas.

Os estudantes não percebem as TICs em outras disciplinas, ou percebem-na de maneira muito tímida, ou seja, a responsabilidade pela abordagem da temática recai sobre a disciplina 'Comunicação e Tecnologia', apesar da coordenação do curso acreditar que a discussão tecnológica se faz presente em diversos momentos do curso, embora estas discussões não alcancem os estudantes, conforme explicitado por eles.

As professoras entrevistadas lembram que não há interdisciplinaridade, o que seria fundamental para a disciplina 'Comunicação e Tecnologia', já que a mesma é curta, conforme opinião de todos os entrevistados, sendo um semestre considerado pouco tempo para todas as possibilidades oferecidas pelo campo. A falta de interdisciplinaridade pode refletir a inexistência de um Projeto Pedagógico ou sua má execução.

Volta-se à questão da falta e precariedade dos aparatos tecnológicos disponíveis na instituição, problema descrito pela coordenadora do curso. Contudo, para o ensino prático não são, obrigatoriamente, necessários esses instrumentos, como exemplos dados pelas professoras, seja por meio da vivência em campo pelos estudantes, seja pela aproximação do campo por meio de profissionais da área, é possível um contato prático.

Vale ressaltar a abertura da "Instituição U" para esta pesquisa e, mesmo, as discussões que têm sido realizadas em seu interior com o objetivo de uma reforma curricular que, segundo 
os levantamentos desta pesquisa, se faz extremamente necessária.

Ficam, no entanto, lacunas no fato de as aulas da disciplina 'Comunicação e Tecnologia' não terem sido acompanhadas, o que pode ser uma sugestão para futuras pesquisas nesta temática. Poderiam, ainda, ter sido entrevistados outros professores da mesma instituição para que as colocações sobre os projetos integrados fossem discutidas por eles. Outra lacuna diz respeito ao aprofundamento na questão do Projeto Pedagógico e acompanhamento de sua aplicação na prática diária da graduação em Comunicação Social.

Espera-se, contudo, que este trabalho contribua com as discussões sobre a inserção das Tecnologias da Informação e Comunicação na graduação em Comunicação Social, possibilitando horizontes mais bem definidos na relação entre os dois campos na academia, com resultados na formação dos comunicadores sociais.

\section{Referências}

BARDIN, L. Análise de Conteúdo. Título original: L'Analyse de Contenu (Presses Universitaires de France, 1977). Trad. Luís Antero Reto e Augusto Pinheiro. Lisboa: Edições 70, 2004 - $3^{\text {a }}$ ed. 223p.

BORDENAVE, J. E. D. Além dos meios e mensagens. Petrópolis: Vozes, 1983. $9^{\mathrm{a}}$ ed. 120 pp.

BUENO, N. de L. \& BRITO, G. da S. Comunicação e tecnologia: da limitação à delimitação nos cursos de comunicação social. UTFPR, In: Simpósio Nacional de Tecnologia e Sociedade, Curitiba: UTFPR, 2005.

FREIRE, P. Educação como prática da liberdade. Rio de Janeiro: Paz e Terra, 1967.

Pedagogia do Oprimido. Rio de Janeiro: Paz e Terra, 17 ed., 23ª reimpressão, 1994.

GOODSON, I. F. Currículo: teoria e história. Petrópolis, RJ: Vozes, 1995. Trad. Attílio Brunetta.

LÜDKE, M.; ANDRÉ, M. E. D. A. Pesquisa em educação: abordagens qualitativas. São Paulo, EPU: 1986.

LUNDGREN, Ulf P. Teoría del Curriculum y Escolarización. Madrid: Ediciones Morata, $1997\left(1^{\mathrm{a}}\right.$ ed.: 1992).

MELO, J. M. de. A Comunicação na pedagogia de Paulo Freire. In: Teorias da Comunicação na América Latina. Petrópolis: Vozes, 1998, pp. 258-283.

. Identidade do campo da comunicação: estratégias para sair do gueto acadêmico. In: Comunicação: discursos, práticas e tendências. BARROS, Antonio Texeira de; DUARTE, Jorge Antonio Menna; MARTINEZ, Regina Esteves (Org.). São Paulo: Rideel; Brasília: UniCEUB, 2001.

PATTON, M. Q. Qualitative evaluation and research methods. $2^{\mathrm{a}}$ ed. Newbury Park: Sage Publications, 
1990.

PERUZZO, C. M. K. Tópicos sobre o ensino de Comunicação no Brasil. In: Retrato do ensino em Comunicação no Brasil. Org.: PERUZZO, Cicília Maria Krohling e SILVA, Robson Bastos da. São Paulo, Taubaté: Intercom UNITAU, 2003. pp. 119-135. Coleção Intercom de Comunicação, v. 16.

SOARES, I. O. Comunicação/Educação: A emergência de um novo campo e o perfil de seus profissionais. Contato (Revista Brasileira de Comunicação, Arte e Cultura), Brasília: Senado Federal, Gabinete do Senador Artur da Távola, ano 1, nº 2, jan./mar. 1999 (www.senado.gov.br/web/senador/tavola/tavola. htm)

SOARES, S. G. Educação e comunicação: o ideal de inclusão pelas tecnologias de informação : otimismo exacerbado e lucidez pedagógica. São Paulo: Cortez, 2006.

TRIVIÑOS, A. N. S. Introdução à pesquisa em ciências sociais: a pesquisa qualitativa em educação. São Paulo: Atlas, 1987.

VIEGAS, W. Fundamentos lógicos da metodologia científica. Brasília: Ed. UNB, 2007. 242pp.

WOLTON, D. Pensar a Comunicação. Brasília: Ed. UnB, 2004. 